\title{
O MUNICÍPIO E A AUTONOMIA LOCAL: ASPECTOS DA DESCENTRALIZAÇÃO DO PODER NO BRASIL
}

David de Medeiros Leite

David Leite é doutor em Direito pela Universidade de Salamanca (USAL). Professor da Universidade do Estado do Rio Grande do Norte (UERN).

\section{Resumo}

A autonomia das administraçôes municipais e a descentralização do poder na realidade brasileira consistem na principal temática do artigo. A partir do estudo da formação das entidades locais, foram feitas investigações com relação à organização e a evolução histórica dos Municípios e as consequências advindas desses aspectos para efetivação do poder local. A análise das competências municipais, tanto de forma exclusiva, cooperativa e complementar, além das atribuições inerentes ao prefeito, merece atenção na medida em que influem decisivamente para que o funcionamento da municipalidade seja instrumento eficaz no atendimento das necessidades básicas dos cidadáos, e, por conseguinte, na consecução da efetivação da descentralização do poder como ferramenta imprescindível no sistema político de um país de dimensões continentais.

\section{Palavras-chave}

Municípios; Administração Local; Autonomia; Sistema Político; Direito Municipal.

\section{Abstract}

The autonomy of municipal administrations and the decentralization of power in the Brazilian reality are the main subject of article. From the study of the formation of local entities of counties, we made inquiries regarding the organization and historical development of municipality and the consequences of these aspects for achievement of local government. The review of municipal competences, either exclusively, cooperative and complementary manner, besides the power of mayor, deserve attention because make a lot of influence for the functioning of municipality be an effective tool in service to basic needs of citizens, and, thus, in attainment of effectuation of decentralization of power as a essential tool in the politic system of a country with continental dimension.

\section{Key words}

County; Local Government; Autonomy; Politic System; Municipal Law. 


\section{Introdução}

$\mathrm{Na}$ discussão geral sobre o tema da democracia, um ponto se destaca a cada dia: a crise de governabilidade. E no meio desta crise, entre muitas alternativas e panaceias postas, ganha força o debate sobre a autonomia dos governos locais. O debate surge com mais força no meio as administraçóes municipais, devido à proximidade entre populaçáo e gestores. Além disso, é neste nível onde os cidadãos podem apresentar suas demandas com mais propriedade, e até conseguir sua resolução havendo menor burocracia no caminho. (PINDADO, 2005).

A autonomia dos Municípios é, portanto, o pano de fundo de nosso trabalho. No entanto, para aprofundar a questão é essencial conhecer a organização político-administrativa do Município, como também o processo de descentralização de poder.

Para melhor compreensão, procuramos esclarecer como o Município funciona no Brasil. Tornou-se necessário buscar elementos a partir do estudo da formação dos Municípios, obrigando-nos a fazer observaçóes sobre a competência do sistema de autonomia e a evoluçáo histórica do Município e a competência do prefeito, considerando que todos esses enfoques refletem diretamente nos interesses dos cidadãos.

Portanto, este artigo terá a seguinte divisão: a organização político-administrativa do Município no Brasil. Com subtítulos: o desenvolvimento histórico do Município, a autonomia municipal, a competência do Município e o papel do prefeito.

\section{A Organização Político-Administrativa do Município no Brasil}

\subsection{Evolução Histórica}

No Brasil, temos que tratar de organização municipal a partir da descoberta e colonização do país por Portugal, em 1500. Durante a fase colonial, Portugal nunca implementou no Brasil, um plano de organização territorial constituída com Municípios de maneira adequada ou até mesmo a partir do modelo existente naquele país.

Historicamente, quando os reinos de Portugal, Espanha, Holanda e Grã-Bretanha iniciaram suas viagens de descobrimentos, se formaram dois tipos de colônias: a colônia de povoamento e a colônia de exploração. A primeira, como seu próprio nome indica, servia simplesmente para aumentar o território do reino, com o objetivo, por um lado, de torná-lo o maior possível, gerando possibilidades como, por exemplo, a de segregação de presos e, por outro lado, para alcançar a formaçáo que lhe favorecesse. De outra banda, as colônias de exploração serviam, como o próprio nome já sugere, para que o reino obtivesse através delas frutos que lhe enriqueceria.

Os principais modelos dos tipos de colonização acima referidos são: os Estados Unidos, como colônia de povoamento, e a América Latina, como colônia de exploração. 
Especificamente, no caso do Brasil, como, de princípio, não existia a intenção de povoar, tampouco houve interesse por organizar o Município no sentido que temos hoje. De forma que a autonomia municipal, em seu principal sentido da palavra, só veio tomar forma muito tempo depois do descobrimento. Segundo José Nilo de Castro, o início da municipalização respondia ao modelo português:

Pondo os pés no Brasil, trouxeram os portugueses, em 1500, as instituiçôes municipais segundo o direito lusitano, com a seguinte organizaçáo: a) um prefeiro; b) juízes ordinários; c) conselheiros (de Câmaras); d) almotacés com funções administrativas subalternas; e) procuradores (advogados representantes do Município); f) os homens bons. (CASTRO, 2006, p. 11)

A princípio, os "Municípios" foram formados com base na necessidade de uma organização mercantil e do próprio povoamento do território, assim também tendo em vista as necessidades sanitárias, ou com o objetivo de execução de obras para servir a todos aqueles que viviam nas aldeias e vilas.

Se personificarmos o Município no Brasil, as vilas seriam seus antepassados mais remotos. Sobre o nascimento das vilas:

A primeira foi Sáo Vicente, em 1521, fundada por Martin Afonso; antes de ter sua carta [doação]; em 1546, Santos; em 1560, São Paulo; e Itanhaém, em 1561. O surgimento dos municípios pode ser visto mais como uma necessidade das comunidades que viviam em solo brasileiro para os desígnios de Portugal. (CORRALO, 2006, p. 56).

Como podemos observar através dos próprios nomes das vilas que estavam sendo criadas, a igreja também influenciou fortemente a fundação das mesmas e de outras organizaçóes nucleares. A Igreja Católica, no Brasil, viu a necessidade de catequese dos povos nativos em nome da mensagem cristá, que ajudou tanto a exploração dessas áreas, muitas vezes inacessível, como na estruturação em forma de cidade para essas comunidades (CASTRO, 2006).

A regulamentação do Município como formação jurídico-administrativa vinculada a algum ordenamento se concretiza no momento em que Portugal impôs à colônia o cumprimento das Ordenaçóes Manuelinas, Alfonsinas e Filipinas, derivada da intenção de criar um lugar de administração geral na colônia.

Essas regulamentaçóes, que datam da segunda metade do século XVI e princípios do século XVII, tinham como finalidade dotar as capitanias de um poder administrativo organizacional com a criação de várias funçóes e de Câmaras nas vilas que foram formadas.

Em termos formais, as constituiçóes brasileiras começaram a refletir a forma do país de ver a organização municipal a partir da Constituição de 1824, que abriu as portas para a sistematização administrativa local. 
Nelson Nery, sobre a importância da Constituição de 1824 para a organização local, comenta que:

O texto constitucional tratava com apreço os Municípios, preceituando que haveria Câmaras em todas as cidades e vilas já existentes, assim como nas que fossem criadas no futuro. Por outro lado, a estas correspondia o governo econômico e municipal das localidades integrada por conselheiros e o Presidente seria o mais votado. Por último, uma lei reguladora deveria decretar as funçôes municipais da Câmara, assim como a formação das ordenaçóes policiais, à aplicação das rendas e demais particularidades e atribuições. (COSTA, 2006, p. 49)

Essa lei complementar entrou em vigor em 01 de outubro de 1828, regulamentando toda organização das Câmaras Municipais, perdurando sua vigência até 1889, ano da proclamação da República. Após dois anos da proclamação da República, foi promulgada a Constituição de 1891, que não trouxe maiores modificaçóes em relação aos Municípios, considerando o que estabelecia a Constituição anterior e a lei referida.

Com relação a este período, o que fica bastante claro é que se concedeu uma grande importância aos estados da federação, lhes outorgando grandes poderes de organização e diminuindo a autonomia das entidades locais, como os municípios e as vilas, mantendo estas sempre sujeitas as decisóes adotadas pelos estados, sem lhes dar qualquer poder em relação à organização administrativa superior.

Embora a Constituição de 1934 tivesse a intenção de outorgar autonomia às autoridades locais, causando uma renovaçáo da capacidade de ter poder próprio e atender às suas próprias necessidades, com o golpe ditatorial de 1937, a evolução do Município fornecida por aquela Constituição foi colocada em xeque.

O Município, além de deixar de ter poderes para resolver seus problemas, acabou perdendo a possibilidade de exigir do Estado que os resolvessem de uma forma mais prática.

Na efervescência do pós-guerra, em 1945, os militares derrubaram o governo ditatorial e, restabelecendo a ordem democrática, provocaram nova possibilidade de modelo administrativo local. Esta alternativa de novo governo gerou uma nova Constituição Federal no país, no ano de 1946, que ampliou os poderes que o Município tinha e lhe outorgou outros novos, ainda que houvesse uma forte interferência da União especificamente nos Municípios que tinham em sua área algum interesse de relevante valor administrativo, financeiro ou militar. Corralo (2006, p. 84-85) aborda a questão da seguinte forma:

Novamente o município pode exercer autonomia, feixe que penetrou no administrativo, político, financeiro e legislativo. No entanto, ainda havia resquício de um modelo concentrador na nomeação dos prefeitos das 
capitais, das instâncias hidrominerais e das localidades estratégicas para a segurança nacional.

Em 1964, o Brasil sofreu um golpe militar e mesmo estando em vigor a Constituição de 1946, o país passou a ser legislado por Atos Institucionais, Atos Complementares e Emendas Constitucionais. Porém, o municipalismo sofreu poucas modificaçóes, principalmente em razão do poder dado ao Executivo. Em 1967, o Brasil teve uma nova Constituição baseada na anterior, nas leis e em outras situaçóes políticos-circunstanciais ocorridas entre 1964 e 1967.

A Constituição de 1967, juntamente com a Emenda Constitucional n o 01 de 1969 fizeram a relação com os Municípios um pouco mais rígida. A designação de prefeitos em algumas situações se manteve, incluindo nas capitais, só que desta vez a referida designação competia ao governador do Estado a qual pertencia à cidade.

O Brasil viveu um período marcado pelo poder ditatorial e só no final da segunda década do referido período é que se tem início uma abertura política que enseja o regresso dos exilados políticos e outras medidas democráticas. Uma população organizada em movimentos políticos em defesa de eleições diretas, anistia, assembleia constituinte, além de outras bandeiras, faz com que o país retorne a normalidade democrática.

Após o longo período ditatorial, com o processo de redemocratização deflagrado em 1985, veio a Constituição de 1988, considerada "Constituição Cidadã”. Esta Constituição, na história do Brasil, tem sido a que mais garante a cidadania e os direitos de uma forma geral, como também, oferecendo aos Municípios abertura e força nunca antes vista no sistema jurídico brasileiro. Hely Lopes Meirelles (2006, p. 44-45), de forma pertinente, comenta:

A principal característica da Carta é a extensão da autonomia municipal para aspectos políticos, administrativos e financeiros, tal como estabelecido nos artigos 29 a 31, 156, 158 e 159, dando também o poder de fazer sua Lei Orgânica (própria carta).

É oportuno dizer que esta organização estabelecida nas Leis Orgânicas Municipais é bastante peculiar do Brasil e difere enormemente de outros países, como, por exemplo, a Espanha, que mantém uma organização administrativa local muito distinta, com uma única lei que serve para todas as localidades do país, sem preservar a mesma singularidade da legislação em voga desde 1988 no Brasil.

Outra característica importante que também trabalharemos adiante é a implícita autonomia auto-organizativa dos Municípios. Com isso, eles não têm mais a necessidade de viver subordinado aos Estados ou a União, podendo, a partir da observação do táo propalado interesse local, organizar-se sem a interferência do Estado. A autonomia serve parar fixar o poder, assegurado pela Constituição Federal. 


\subsection{Autonomia Municipal}

Autonomia nos Municípios brasileiros representa a "independência" funcional em relação aos Estados e a União. A autonomia regular e vasta obtida a partir da Constituição Federal de 1988, fez com que os Municípios gozem de atribuições, que em outros momentos só foram desfrutadas pelos demais entes federados, sobretudo ao ser conferida a possibilidade de uma autorregulaçáo administrativa abrangente. Sobre essa busca da autonomia, Urbano Vitalino (1999, p. 41) afirma que:

A dimensão territorial impressionante fez com que nosso país, desde sua criação, adotasse o sistema generalizado de divisão territorial de poder, divididos pelas várias unidades políticas que os compóem, sendo outorgada a cada uma, certas e específicas competências. O esquema dos centros regionais autônomos e comunidades tem sido mantido até hoje em nossas Cartas Constitucionais, sem prejuízo das competências do núcleo central, inclusive, reservando-se o direito de emitir princípios gerais de política, como guardião da unidade nacional.

Em outro sentido, Hely Lopes (2006, p. 108) conceitua autonomia administrativa e, como lhe é característico, nos brinda com importantes e exatos conceitos:

O conceito de administração própria não oferece dificuldade de entendimento e delimitação - é a gestâo dos negócios locais pelos representantes do povo do Município, sem interferência dos poderes da União ou do Estado membro -. Mas a cláusula limitativa dessa administração exige uma exata interpretação, para que o Município não invada competências alheias, nem deixe de praticar atos que lhe são reservados. Tudo se resume, portanto, na precisa compreensão no significado de "interesse local".

A autonomia administrativa municipal brasileira serve para situar os Municípios na encadeada organizaçáo dos membros federados. Essa autonomia deve se reger com base no interesse local, ou seja, o peso da opiniāo interna sobre certas questóes deve prevalecer. A municipalização da força administrativa, muito mais que uma busca por parte das localidades brasileiras, surgiu da necessidade de uma administração própria e particular focada nas questóes locais, onde o Estado membro e a União não alcançariam resolver questôes peculiares.

A autonomia municipal refere que o Estado membro não possui determinadas atribuiçóes que concerne única e exclusivamente ao Município. Portanto, a autonomia também cabe em questóes em que todos os âmbitos da federação têm o dever de estar presente, tanto de forma autônoma, como complementar, ou em colaboração com os demais entes.

Durante um longo período da história do país, a autonomia política dos Municípios brasileiros era pequena ou quase nula, por isso, inicialmente, só existia em relação à 
formação das Câmaras Municipais e somente muito tempo depois, surgiu a possibilidade de também eleger prefeitos.

As Câmaras Municipais, ainda que o povo tivesse a possibilidade de escolha dos seus membros, não desfrutavam da prerrogativa de exercer suas funçóes como poder constituído. Mais tarde, com a criação do cargo de prefeito, o quadro dessa autonomia evoluiu.

Nelson da Costa Nery (2006, p. 128) conceitua a autonomia política dos Municípios da seguinte forma:

A autonomia política do Município envolve a qualidade atribuída a estrutura do poder político local, e da relação entre eles. O Município tem a capacidade, portanto, para organizar e formar seu próprio governo. Apesar de não haver hierarquia entre os três entes federativos, deve haver uma limitação da forma de organização, porque os princípios são estabelecidos nas Constituiçôes Federal e Estadual.

Portanto, se apresenta sinteticamente a melhor dedução para autonomia administrativa, como a possibilidade de que o Município constitua e mantenha seu próprio governo no campo administrativo local. Este "constituir e manter" toma também outras possibilidades com relação à organização administrativa local, com a possibilidade de destituir a quem goze desse direito político sem estar de acordo com o que a legislação nutre ou permite ou, em outro caso, efetue uma conduta qualificada de ilegal ou inadmissível para alguém que exerce uma função pública como a de prefeito ou vereador.

A possibilidade de anular o exercício da função de prefeito ou vereador também é uma forma democrática de estabelecer essa autonomia política, de forma que, em alguns casos, existe uma inquietude quando se fala de quem seria a competência definitiva dentro da organização administrativa municipal. A força dessa autonomia acaba fazendo com que o Município exerça um controle sobre seus próprios representantes.

A Carta de 1988 ofereceu ao Município a possibilidade de exigir tributos de seu interesse, sobre o que for de sua competência, mostrando que, mais uma vez, o interesse local superou a entidade centralizadora maior.

Ademais da possibilidade de arrecadar tributos de sua competência, o poder público municipal também pode criar taxas, contribuiçóes especiais e outras contribuiçóes. Em outros tipos de impostos, o Município recebe, tanto do estado como da Uniáo, uma parte do que eles arrecadam, mesmo que o Município não tenha competência para legislar sobre os referidos impostos.

No que se refere ao planejamento orçamentário, o Município também tem a competência de organizar seu Plano Plurianual, a Lei de Diretrizes Orçamentárias e a Lei Orçamentária Anual. É oportuno ressaltar que, mesmo diante da automia orçamentária, 
o Município está vinculado às previsôes constitucionais de aplicação de uma porcentagem fixa para a educação pública e outros percentuais assim definidos.

Quando falamos de autonomia para auto-organização, estamos falando especificamente do poder que o Município tem de desenvolver a sua própria "Constituição", que é chamada de "Lei Orgânica". Embora a Lei Orgânica deva respeitar tanto a Constituição Federal como a Constituição do Estado, de modo que não se pode legislar em sentido contrário aos preceitos já designados por ambas, sendo uma condição prévia de que o Poder Legislativo municipal as acate no momento de confeccionar a referida Lei Orgânica, esta serve para que o Município reflita e protagonize o interesse local.

A possibilidade do Município se organizar a partir de uma lei maior própria é a principal característica da autonomia de auto-organização. A esse respeito, Corralo (2006, p. 209) expóe uma consideração com relaçáo a outras repúblicas do mundo, dizendo que:

A autonomia de auto-organização do Município brasileiro lhe leva a ter um tratamento constitucional singular federalista, pois tal possibilidade somente foi outorgada aos estados e não aos Municípios. A auto-organização é uma característica inerente dos entes federados, o que reforça a posição do Município como ente integrante da federação brasileira.

A previsão da necessidade de uma Lei Orgânica de organização do Município se materializa no artigo 29 da Constituição Federal (BRASIL, 1988, p. 31), quando alega que "O Município reger-se-á por lei orgânica, votada em dois turnos, com o interstício mínimo de dez dias, e aprovada por dois terços dos membros da Câmara Municipal”.

O fato é que, na verdade, em um país com mais de cinco mil Municípios, onde há uma significativa diferença entre as pessoas e as suas necessidades, onde em cada local há grandes diferenças e peculiaridades, a decisão do Estado de obter para si a possibilidade de impor uma organização perfeitamente igual a todos os Municípios parece pretensioso a ponto de atrapalhar ao invés de ajudar. (RESENDE, 2008).

Este poder de legislar no âmbito local abrange três tipos diferentes: a possibilidade de legislar é exclusiva, para os casos com um interesse local proeminente; a possibilidade de legislar é compartilhada, quando o Município, os Estados e a União podem legislar sobre um determinado assunto; e a possibilidade de legislar é complementar quando, por haver um interesse local envolvido, o Município age em situaçóes onde outros entes federais não o fazem.

\subsection{Competência dos Municípios}

Competência, no sentido aplicado neste artigo, é o ato de ter aptidão para realizar determinada ação, o que, de fato, é o próprio trabalho de campo da entidade municipal, 
que busca, por esse meio, a satisfação de sua atuação e, por conseguinte, de atender o interesse coletivo.

A competência administrativa refere-se à capacidade para gerir o Município, competência que cada ente tem para si de acordo com sua situação. Fazendo uma análise das competências do Município, o autor José Nilo Castro afirma que (2006, p. 197):

A jurisdição do município deriva da Constituição Federal. Nossa Federação adotou a tripartiçãoo dos poderes. Os poderes da União e Municípios são explicitamente listados na Carta da República, reservando aos estados o poder que não são proibidos.

O interesse local, de fato, em ocasiōes, não está perfeitamente caracterizado na Constituição quando se trata de competência privativa, de forma que também pode satisfazer no que diz respeito à competência complementar, que abrange a questão quando náo há competência privativa de nenhum ente federativo e sempre quando a mesma questão seja resolvida em razão do referido interesse.

Braz (2006) exemplifica como problemas de interesse local: abastecimento, esporte e lazer. O autor de Direito Municipal na Constituição assevera que o termo abastecimento, não se refere apenas a comida, mas também abrange água e energia elétrica para toda a população.

Em outro âmbito, quando o patrimônio histórico municipal está correndo riscos, cabe ao próprio Município prover os meios necessários para protegê-lo, sem que se constitua dever de outros entes federativos.

A respeito do meio ambiente, a intervenção municipal se justifica no interesse local, na medida em que for apropriado. Enquanto a União dita regras gerais sobre o assunto, confere aos Estados, da mesma forma que aos Municípios, que resolvam suas questôes no âmbito de sua competência privativa.

Quanto ao combate às causas da pobreza, cabe aos Municípios estabelecer em suas sedes programas desenvolvidos pela União com esse fim, agindo particularmente como gestores especiais através de suas secretarias.

A educação, além da escolaridade obrigatória, envolve o acesso à cultura, dentro ou fora das escolas ou outras entidades financiadas por entes federativos. Noutro ponto, o acesso à saúde também inclui o acesso à assistência social como um meio de proteção da família e garantia constitucionalmente adquirida por trabalhadores em geral.

É oportuno esclarecer que, com a Constituição de 1988, houve no Brasil uma ampliação enorme dos acessos aos serviços de saúde pública. Foi necessário descentralizar o poder nesta matéria, o que possibilitou que o Município também acabasse sendo um gestor da saúde pública, organizando sua prestação. 
Petrônio Braz (2006, p. 177), falando sobre a possibilidade de cooperação entre os entes federados, diz que o ordenamento pátrio oferece meios para a consecução desse fim:

Existe a competência de cooperação quando uma entidade federativa, a quem não compete originariamente a atribuição funcional para a prática de certos atos administrativos, se adentra de forma válida ou por disposição legal na esfera funcional de outra, com vistas a atender os fins do Estado, em sua concepção genérica. Ao Município compete manter, com a cooperação técnica e financeira da União e do estado, programas de educação pré-escolar, de ensino fundamental, assim como prestar serviços de atenção a saúde da população.

Nessa análise de Petrônio Braz, observamos que a competência de cooperação consiste, na realidade, em prestaçóes que os entes federativos hão de entregar aos cidadãos, para cuja consecução os entes se veem obrigados a se unirem.

E sobre competência complementar Petrônio Braz (2006, p. 194) expóe:

(...) é a que se estabelece por ampliação, permitindo a solução de possíveis conflitos, atribuindo-se aos Municípios capacidade para elaborar leis, em atenção ao interesse local, que versa sobre a matéria não definida em sua competência exclusiva. A Constituiçấo Federal proporcionou aos Municípios os mais amplos poderes para complementar, em assuntos de interesse local, as legislaçôes federal e estadual.

A delimitação dessa competência complementar é aberta, em virtude da própria autonomia legislativa dos Municípios. Se a União e os estados ditam a lei que não satisfaz o interesse local, corresponde ao Município suprir essa lacuna legislativa. Por vezes, essa competência pode confundir-se com a competência exclusiva, em razão de que o ente maior não pode fixar regras em situações onde só o Município pode ditar sua legislação em virtude do interesse local. A diferença está se a lacuna afeta a um ato privativo ou não.

É oportuno citar o que Corralo (2006, p. 178) diz sobre a competência complementar dos Municípios:

É desde o prisma do interesse local que o Município pode e deve exercer a competência complementar prevista no artigo 30, II da Constituição, que é uma competência legislativa compartida primária, pois, deriva do próprio texto constitucional. Frente a omissão da União, o Município poderá exercer uma competência complementar através de normas gerais.

Mesmo falando de competência complementar, é possível discorrer sobre a possibilidade estatal de criar consórcios entre Municípios com a finalidade específica de planejar e executar obra pública (sem se falar em outras finalidades temáticas) que seja de interesse de todos os envolvidos no processo. Tal possibilidade requer um consenso legal pela 
necessidade de que certas localidades municipais, grupos de Municípios e regióes metropolitanas organizem situaçóes em comum.

\subsection{Prefeito}

O prefeito é o representante do Município, eleito mediante sufrágio livre de todas as pessoas aptas para votar na correspondente eleição e desenvolve papel primordial na organização púbica e na criação de políticas públicas adequadas para a localidade.

No Brasil, há a divisão dos três poderes: Executivo, Legislativo e Judiciário; como regra, um poder não pode assumir atribuiçóes de outro, de modo que a harmonia entre os poderes da administração pública brasileira é alcançada. Assim, a prefeitura é o centro da administração municipal, dirigida pelo prefeito, a quem vários órgãos, tais como secretarias municipais ou gerencias, são subordinados.

A organização executiva local não tem apenas a função de fazer cumprir as leis que emanam do Legislativo, mas também para organizar as políticas públicas destinadas aos seus cidadãos, buscando uma administração pública mais forte e capaz de solucionar os problemas da população local.

Na organização municipal, os secretários também realizam funçóes como agentes públicos, sendo responsáveis administrativamente pelos seus respectivos setores. Sua designação é atribuição do prefeito. Há uma divisão das tarefas municipais segundos as necessidades, razão pela qual se criam as secretarias.

Mais uma vez recorremos aos ensinamentos de Hely Lopes Meirelles (2006, p. 710), para definição da figura do prefeito:

O prefeito é o chefe do Executivo municipal, agente político, dirigente supremo da prefeitura. Como chefe do Executivo e agente político, tem atribuiçôes governamentais e administrativas. No desempenho do cargo, em que é investido por eleição, não fica submetido hierarquicamente a nenhuma autoridade, órgão ou poder estadual ou federal, somente se sujeita ao controle da Câmara, segundo as normas específicas da administração local, e as leis gerais do estado membro e da Uniáo. Exerce suas funçôes com plena liberdade, no marco da competência funcional e nos limites da autonomia municipal.

A figura do prefeito é para o Município o que o governador é para o Estado e o presidente para a Uniâo, guardadas as devidas proporçôes ao caso que aqui se trata. Como derivação da conquista de poder pelos entes locais, surgiu um Poder Executivo com funçôes locais similares as dos demais chefes das outras duas esferas. Portanto, o prefeito é o representante maior do Município, exercendo a função de representante legal e de autoridade no que se refere à organização municipal local. 
Como "todo o poder emana do povo", cabe à população exercer sua atribuição de escolher a pessoa para o exercício do mandato de prefeito em cada Município. Esse cidadão é eleito por sufrágio aberto e exercerá as suas funções em nome do povo de sua cidade, os seus poderes são previsto pela Lei Orgânica de cada Município, o que, como já mencionado anteriormente neste estudo, é a lei maior.

Convém ressaltar novamente que, para organizar seu poder, o prefeito não está abaixo das ordens de nenhum outro agente político, de modo que exerce sua função de forma independente. Buscando a capacidade plena de trabalho, a independência funcional é uma garantia do pleno exercício do mandato eletivo do poder público municipal.

Cabe ao chefe do Executivo municipal designar todos os secretários municipais, a fim de descentralizar a administração e proporcionar ao prefeito maior capacidade de gestão, para que se atinja a satisfação administrativa plena, em todas as áreas.

O prefeito realiza seu papel mediante atitudes que tratem de questóes diretas, cujo fundamento seja resolver situaçóes ou potenciar uma melhor qualidade de vida nos Municípios. Quando falamos sobre os poderes do prefeito no exercício do seu cargo de chefe do Executivo municipal, é importante retornar ao que Hely Lopes Meirelles (2006) ensina. Ele afirma que os poderes do prefeito e chefe Executivo municipal é dividido em dois tipos distintos, a saber: autoridade política e atribuiçôes de caráter administrativo.

Há atos administrativos do prefeito que possuem a qualidade de vinculantes e outros não, que integram a gestão própria dele. Da mesma forma que existem atos do prefeito que devem ser aprovados pela Câmara Municipal para ser validado, enquanto outros não necessitam.

O prefeito também será responsável por assegurar a equidade e organizar questóes orçamentárias municipais, incluindo a Lei Orçamentária Anual (LOA), a Lei de Diretrizes Orçamentárias (LDO) e o Plano Plurianual (PPA).

Compete também ao prefeito organizar as obras necessárias para o Município e os cidadãos, assim como organizar o pessoal vinculado à prefeitura para a execução das atividades que lhes são próprias em nome do princípio da eficiência. Cremos oportuno citar Cretella Júnior (1981, p. 29):

Pelo próprio princípio do poder-dever, o administrado municipal tem não só a faculdade, o direito e prerrogativa de atuar, mas também o dever, a obrigação de tomar providências em determinados casos previstos em lei, sob pena de incorrer em responsabilidades, como acontece, por exemplo, na instauração de uma investigação administrativa, quando a natureza da falta assim o exija, ou em caso de aplicação de sansóes.

É oportuno ressaltar que o prefeito não é funcionário público, e sim um agente político, o que lhe corresponde às disposições relativas aos governantes. Hely Lopes (2006, p. 
775) analisa a responsabilidade do prefeito afirmando que pode existir um triplo aspecto: penal, político-administrativo e cível. Cada um se desenrola em processos independentes.

A responsabilidade penal do administrador público municipal se refere a todo ato que resulte na consumação de um delito, tanto no âmbito do código penal como no âmbito de uma lei específica dessa área. Quanto a responsabilidade político-administrativo se refere a qualquer transgressão que atente contras os aspectos éticos da função de prefeito e que podem levar a sua cassação. Essas situaçôes são previstas nas leis orgânicas dos Municípios, em leis especiais e na Constituição Federal em seu artigo 29-A, parágrafo 2º I, II e III. E a responsabilidade civil diz respeito às questóes que o prefeito náo cumpre, tendo que ressarcir as finanças públicas alguma despesa ou outras questôes ligadas ao orçamento municipal.

\section{Conclusões}

No presente artigo tivemos a oportunidade de aprofundarmos a questáo da organização do município no Brasil, observando aspectos do direito no âmbito municipal, e, por conseguinte, peculiaridades do poder local.

O "poder local" traduz a prerrogativa autoadministrativa dos Municípios, como também a capacidade de administrar os interesses públicos locais. E, consequentemente, sempre que se analisa a questão das competências dos entes locais, incidi-se, obrigatoriamente, na análise de temas correlatos como o "interesse local", o "poder local" e a "descentralização".

Dentro de todo contexto estudado, vale ressaltar que uma primeira conclusáo nos remete a um aspecto muito importante, qual seja: o caráter funcional dessa autonomia local, que diz respeito à organizaçáo da administraçáo, dos serviços que se devem prestar e da forma que essa função está intimamente ligada às prerrogativas da entidade local de assumir deveres comuns, que, por conseguinte, passam a ser de sua competência a partir das previsôes legais.

Para tanto, a autonomia é imprescindível em relação aos assuntos que o ente local tem maior pertinência, ou seja, no que diz respeito a organizar políticas públicas com o objetivo de satisfazer as necessidades da população local, na incessante busca de alcançar o bem-estar social no meio comunitário.

E para viabilizaçáo do objetivo primordial de satisfazer necessidades da população, o fator funcional é pedra angular. Nesse sentido, o fator funcional se refere à execução de função relativa ao conjunto de competências que podem ser desenvolvidas pelo Município, incluindo o conteúdo dessas funçôes, preferencialmente na intervenção social e econômica. 
O pensamento doutrinário comentado se aplica obviamente à realidade brasileira, com ênfase no sentido de que as funçôes da municipalidade devem funcionar em quaisquer das circunstâncias, favorecendo o bom funcionamento da área administrativa local em favor do interesse dos cidadãos.

Outra conclusão diz respeito ao fato de que, no Brasil, a autonomia municipal e a força na formulação de suas competências, tem como pressuposto principal a necessidade de defender o caráter descentralizador, assim como o interesse local de cada município. Esse caráter descentralizador proporciona que as açóes do Executivo local supram de forma mais eficaz às necessidades do cidadão.

No Brasil, como bem explorado no decorrer do trabalho, cada município cria sua própria Lei Orgânica municipal, significando que a organização municipal brasileira possui maior efetividade, considerando uma forte necessidade de descentralização do poder executivo, uma vez que nosso país é de proporçóes continentais, com pluralidade de culturas, diversidade ambiental, etc.

Diante de tudo, é possível concluir ainda que os aspectos da evolução histórica dos Municípios, da autonomia, da competência e, ainda, das atribuições dos prefeitos, interferem no poder local e, consequentemente, refletem diretamente os interesses dos cidadãos.

Assim, o Município, sem dúvida alguma, caracteriza-se como ente público que está mais próximo ao cidadão e, consequente, pode resolver de forma mais efetiva os problemas que mais afetam a coletividade.

\section{Referências}

BRASIL, Constituição. Constituição da República Federativa do Brasil. São Paulo: Editora NDJ, 2012.

BRAZ, Petrônio. Direito Municipal na Constituição. 6. ed. São Paulo: Mizuno, 2006.

CABAllero, Francisco Velasco. Autonomía Municipal. In: II Congreso de la Asociación Española de Profesores de Derecho Administrativo. 2007. Disponível em: <http://grupos.unican.es/ada/2007\%20AEPDA/Autonomia\%20Local_Velasco. pdf> Acesso em 03 de maio de 2014.

CANOTILHO, José Joaquim Gomes. Direito Constitucional e Teoria da Constituição. Almedina, Coimbra. 2003

CASTRO, José Nilo de. Direito Municipal Positivo. Del Rey, Belo Horizonte. 2006

CORRALO, Giovani da Silva. Município - Autonomia da Federação Brasileira. Juruá, Curitiba. 2006.

COSTA, Nelson Nery. Direito Municipal Brasileiro. 3. ed. Forense, Rio de Janeiro. 2006. 
LEITE, David de Medeiros. Presupuesto Participativo en municipios brasileños: Aspectos Jurídicos y Administrativos. Madrid: Editorial Académica Espańola, 2012.

LOZANO, Fernando Cordeiro. El pacto local: un punto de partida. Disponível em: $\quad$ http://dialnet.unirioja.es/servlet/fichero_articulo?codigo=266037\&orden=90225> Acesso em: 05 de maio de 2014 .

MACHO, Luis Miguez. El régimen de las grandes ciudades. In: La Modernización Del Gobierno Local. Atelier, Barcelona. 2005.

MEIRELLES, Hely Lopes. Direito Municipal Brasileiro. Malheiros, São Paulo. 2006.

MELLO FILHO, Urbano Vitalino. Direito Municipal em Movimento. Del Rey, Belo Horizonte. 1999.

ORDUNAA REBOLLO, Enrique. La administración local en la constitución de 1978. Disponível em: < dialnet.unirioja.es/descarga/articulo/1111910.pdf> Acesso em: 05 de maio de 2014.

PÉREZ, M Antonia Ramírez; MARTÍNEZ, Cecilia Pitt; YÁÑEZ, Clemente J. Navarro. La estructura de oportunidades de la política local. El caso de los municipios andaluces. Revista de Estudios Regionales, no 79, pp. 99-126. 2007.

PINDADO, Fernando. La participación no se improvisa. Revista de estudios locales, Madrid, Num. 87, p. 10. 2005.

QUESADA, Miguel-Ángel Ladero. Las ordenanzas locales. Siglos XIII-XVIII, En la España Medieval.. Servicio de publicaciones, Universidad Complutense, Madrid, $\mathrm{n}^{\circ}$ 21, p. 294-295. 1998.

RESENDE, Antônio José Calhau de. Autonomia Municipal e Lei Orgânica. Caderno Escola Legislativa, Belo Horizonte, v. 10, n. 15, pp. 7-42. 2008.

SÁNCHEZ SÁNCHEZ, Zulima. Estudio Práctico de las asociaciones - Democracia directa y otras formas de participación ciudadana. Lex Nova, Valladolid. 2004.

VELASCO, Joaquín Huelín Martínez de. Globalización y principio de autonomía local. Consejo General del Poder Judicial, Madrid. 2008

WAGNER, Francisco Sosa. Manual de Derecho Local. Aranzadi. Navarro. 2005. 